Review

\title{
Supramolecular Gold Metallogelators: The Key Role of Metallophilic Interactions
}

\section{João Carlos Lima ${ }^{1, *}$ and Laura Rodríguez ${ }^{2, *}$}

1 REQUIMTE, Departamento de Química, Centro de Química Fina e Biotecnologia, Universidade Nova de Lisboa, Quinta da Torre, 2825 Monte de Caparica, Portugal

2 Departament de Química Inorgànica, Universitat de Barcelona, Martí i Franquès 1-11, 08028 Barcelona, Spain

* Authors to whom correspondence should be addressed; E-Mails: lima@fct.unl.pt (J.C.L.); laura.rodriguez@qi.ub.es (L.R.); Tel.: +351-212948300 (ext. 10923) (J.C.L.); +34-934039130 (L.R.); Fax: +351-212948550 (J.C.L.); +34-934907725 (L.R.).

Academic Editor: Ahmed Mohamed

Received: 15 October 2014 / Accepted: 11 December 2014 / Published: 31 December 2014

\begin{abstract}
Gold metallogelators is an emerging area of research. The number of results published in the literature is still scarce. The majority of these gels is observed in organic solvents, and the potential applications are still to be explored. In this work, we present an overview about gold metallogelators divided in two different groups depending on the type of solvent used in the gelation process (organogelators and hydrogelators). A careful analysis of the data shows that aurophilic interactions are a common motif directly involved in gelation involving $\mathrm{Au}(\mathrm{I})$ complexes. There are also some $\mathrm{Au}(\mathrm{III})$ derivatives able to produce gels but in this case the organic ligands determine the aggregation process. A last section is included about the potential applications that have been reported until now with this new and amazing class of supramolecular assemblies.
\end{abstract}

Keywords: gold; gels; supramolecular; aurophilic interactions; applications

\section{Introduction}

Low-molecular-mass gelators (LMGs) represent a key area in the study of supramolecular chemistry because of their spontaneous and controlled self-assembly phenomena [1]. In many cases, LMGs are 
formed upon their self-assembly through a combination of non-covalent interactions such as $\pi-\pi$ stacking, hydrogen bonding, hydrophobic-hydrophobic interactions and van der Waals' forces, resulting in the formation of entangled self-assembled fibrillar networks (SAFINs) [2]. Interestingly, the fine balance and the interplay of the non-covalent interactions in these gelators can be readily modified by the judicious choice and rational design of the coordinating ligands in the organometallic systems, which in turn may give rise to a fine tuning of the gelation properties and morphologies of the low molecular weight gelators (LMWGs).

Amongst the fields of supramolecular chemistry, low molecular weight gelators are also called supramolecular gelators. They have attracted increasing attention because of their wide applications in our daily lives, ranging from commercial products like hair gel and contact lenses to drug delivery for medical purposes [3-5] and a number of high-technology applications [2,6-8], materials chemistry [9-11] use in light harvesting [12], sensing [13] or catalysis [14].

Though gel formation by organic molecules has been widely reported, metallogels have only been a subject of study in the last few years [6,15-18]. The reason for the growth of interest stems from the availability and the diversity of metal-ligand coordination that could readily induce or control the self-assembly process of the gel formation and thereby influence the gel properties [6].

Metallogelators may consist of coordination polymers or discrete metal complexes that form supramolecular assemblies or aggregates. In these particular cases, the presence of metal ions in their chemical structure gives rise to exciting potential applications of metallogels that include catalytic activity [19,20], bioimaging [21,22], controlled release [5], redox-induced switching of gel-sol transitional behavior [23], magnetism, color, rheology, adsorption, and photophysical properties [24]. A supramolecular gel consists of a large amount of liquid (solvent) and a small amount of solid (gelator); the solvent molecules are immobilized within the gel matrix formed by hierarchical self-assembly of the gelator molecules [25]. When a metal complex serves as a gelator, metal-ligand coordination interaction can be used to form the 3D matrix. The possible establishment of metallophilic interactions in some particular metal complexes also plays a key role for the primary aggregation in metallogels and may lead to variation in the gelating abilities and rich photophysical properties [6,26-32].

Supramolecular gels are classified into two categories: Organogels and hydrogels. As indicated by the name, organogel represents gelator molecules that immobilize organic solvents while hydrogel represents molecules that immobilize water.

In contrast to the development of coordination polymeric gelators, the use of discrete small-molecule complexes as metallogelators has been relatively scarce, and it was only recently that a number of reports on the gelation properties of metal complexes, mainly $\mathrm{Au}(\mathrm{I})$ and $\mathrm{Pt}(\mathrm{II})$ derivatives, have appeared. Upon the introduction of appropriate functional groups, the functionalized metal complexes can undergo self-assembly through non-covalent interactions such as hydrogen bonding and hydrophobic-hydrophobic interactions [6]. Nevertheless, the formation of these supramolecular assemblies sometimes is unexpected [28-30]. It should be stressed that in these cases, apart from the well-known weak interactions of the organic molecules, metal $\cdots$ metal interactions have been found to further stabilize the metallogels formation and give rise to interesting spectroscopic properties. Although the establishment of this kind of interactions is widely observed in solid state (X-ray crystal structure), they are also expected to be maintained in solution and in gel structures, since the formation of supramolecular assemblies has been detected by some techniques such as UV-vis, DLS, NMR or cryoTEM [18]. 
In this review article we will focus on discrete gold complexes that could act as metallogelators since they have been of growing interest in recent years. They will be classified in the same groups (organometallogels and hydrometallogels) depending on the type of solvent (organic solvent or water) immobilized by the gelator gold molecules. Moreover we would like to highlight the key role of aurophilic interactions on supramolecular gold(I) chemistry and gold(I) metallogelators. These $\mathrm{Au}(\mathrm{I}) \cdots \mathrm{Au}(\mathrm{I})$ non-covalent interactions (with maximum distance around the sum of their van der Waals radii, ca. $3.5 \AA$ ) are estimated to be energetically similar to hydrogen bonds (5-10 kcal mol [33]), and a little weaker in the case of other metals like silver(I) and copper(I) [34]. Thus, they should be considered as an additional stabilizing force in the formation of the 3D network in gels being the most important driving force in most of the cases, and the resulting structures were addressed as "metallophilic hydrogels" a few years ago [35].

\section{Gold Organometallogelators}

The vast majority of metallogelators reported in the literature are obtained in organic solvents. It was only in 2005 that the first example of a metallogelator based on trinuclear gold(I) pyrazolate complexes with long alkyl chains was reported by Aida and coworkers [27]. The authors showed the formation of a red-luminescent organogel $\left(\lambda_{\mathrm{em}}=640 \mathrm{~nm}\right)$ with a trinuclear $\mathrm{Au}(\mathrm{I})$ pyrazolate complex bearing long alkyl chains (Compound 1, Figure 1) in hexane via $\mathrm{Au}(\mathrm{I}) \cdots \mathrm{Au}(\mathrm{I})$ interactions. They also showed that the luminescence color can be changed synchronously to thermoreversible sol-gel transition and doping/dedoping of $\mathrm{Ag}^{+}$by the establishment of $\mathrm{Au}(\mathrm{I}) \cdots \mathrm{Ag}(\mathrm{I})$ interactions. Additional van der Waals forces exerted by the long alkyl chains also seemed to be involved on the gelation process. In that case, the red phosphorescence of the metallogels turns blue in the presence of a small amount of $\mathrm{Ag}(\mathrm{I})$ ions. The reversible behavior observed in the presence of $\mathrm{Ag}(\mathrm{I})$ could be modulated by the addition of chloride anions to the solution previously dopped with silver(I) (Figure 2). A gel-to-sol phase transition was observed at high temperatures giving rise to a green phopshorescence in solution.

Recently, Lin and coworkers reported the self-assembly of gold(I) $N$-heterocyclic carbene (NHC) complexes of the general formula $\left[\mathrm{Au}\left(\mathrm{C}_{n} \text {,amide-imy }\right)_{2}\right]$ [anion] where $\mathrm{C}_{n}$, amide-imy stands for a imidazol-2-ylidene carbene (NHC) having one $N$-alkyl substituent $\left(\mathrm{C}_{n} \mathrm{H}_{2 n+1}\right)$ and one $N$-acetamido substituent, and the anions are $\mathrm{Br}^{-}, \mathrm{NO}_{3}{ }^{-}, \mathrm{BF}_{4}^{-}$or $\mathrm{PF}_{6}^{-}$(Compounds 2-5, Figure 1). These complexes showed interesting nanostructures in electron microscopy images with different sizes and shapes depending on the counteranion as described in Figure 3 [36].

These diverse morphologies were believed to result from the formation of hydrogen bonds, hydrophobic-hydrophobic interactions, coulombic interactions, and especially amido hydrogen bonding interactions to give a lamellar structure with tubular architecture around the ionic head core such as long wires, oriental lantern-shaped bundles of belts, and helical belts. In fact, they demonstrated the important role of the amide group as an excellent hydrogen-bonding motif, which gives a tubular architecture around the metal ions in the solid state. Self-assembly of these functionalized NHC complexes leads to the formation of the first example of of gold(I)-NHCs gel probably induced by the presence of the amide groups, since steroid, amino acid or amide derivatives have been commonly employed to promote the formation of gels [37-40]. Interestingly, authors say that the gold(I) ion is crucial for the formation of 
gels since without the gold(I) ion, amido functionalized imidalium salts themselves do not form gels [36]. For this reason, aurophilic interactions probably must be involved in this gelation process as well.

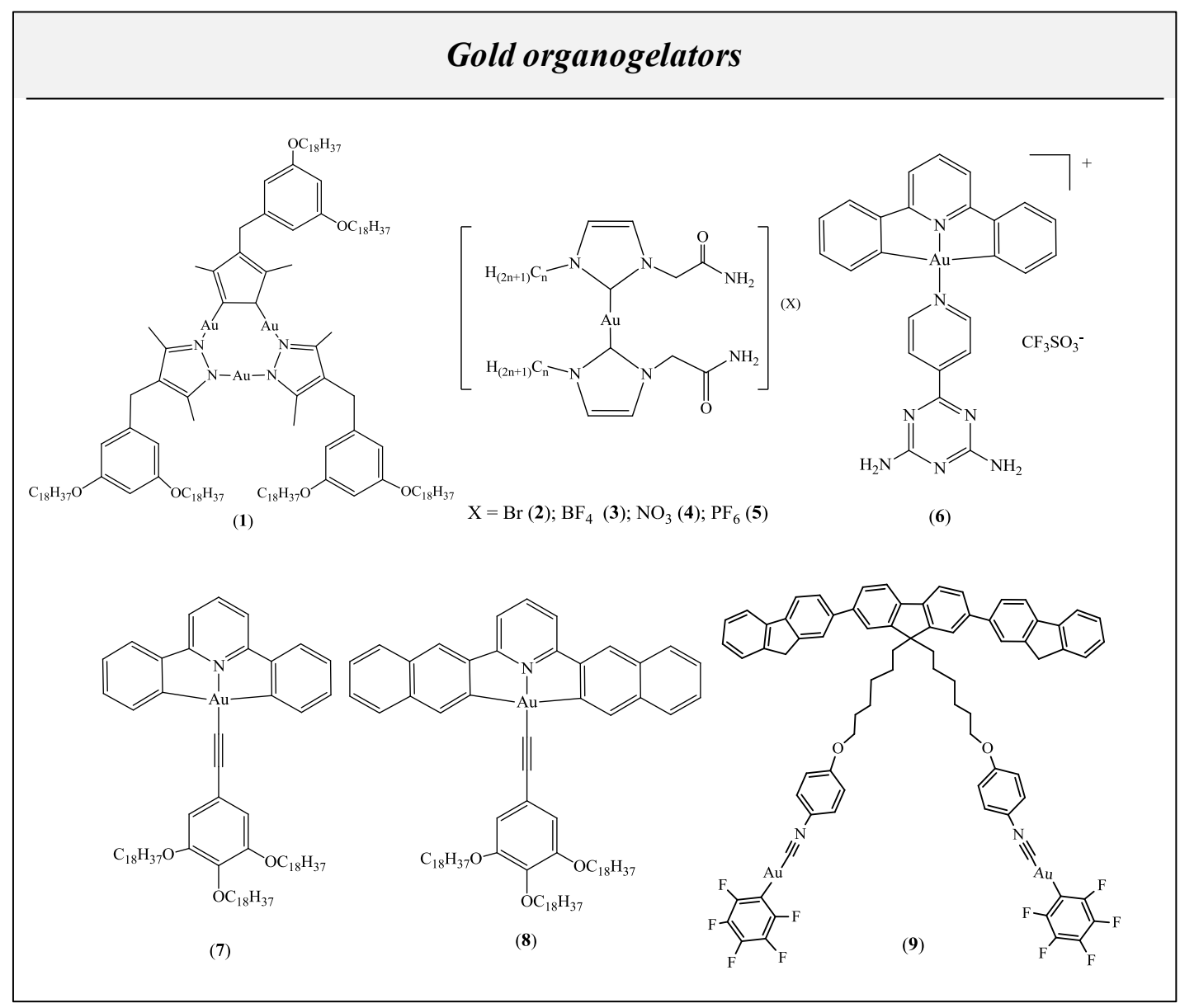

Figure 1. Gold organogelators reported in the literature.

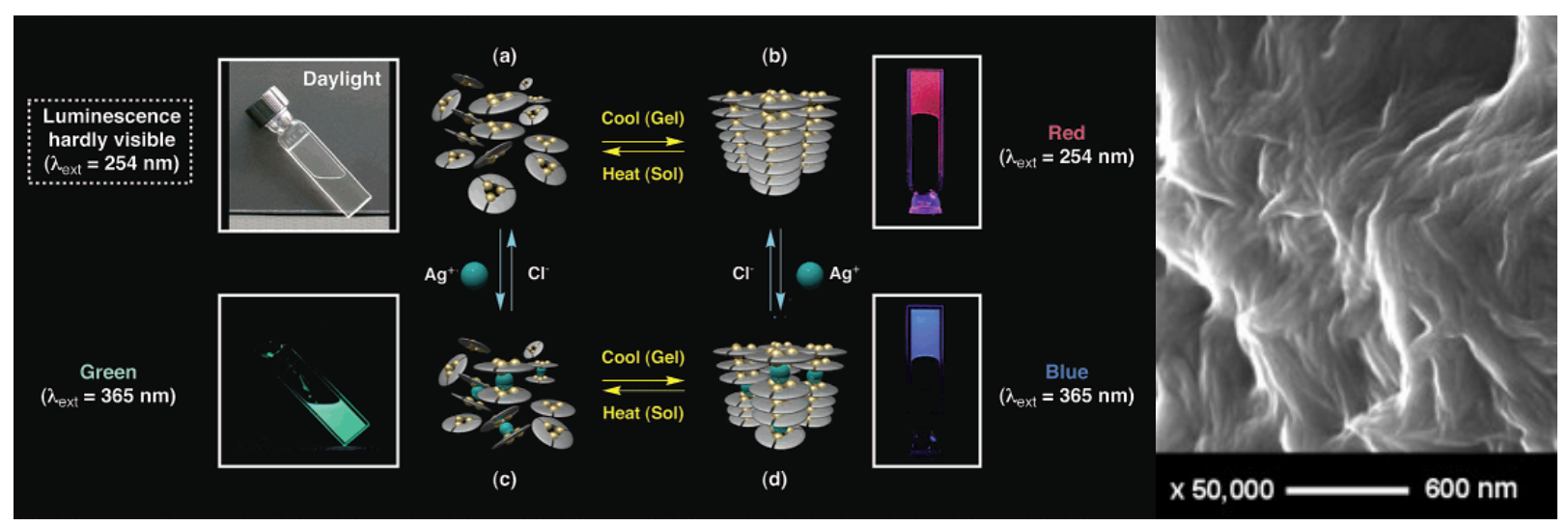

Figure 2. Luminescence profiles of $\mathrm{Au}(\mathrm{I})$ pyrazolate Complex 1 in hexane. Pictures and schematic self-assembling structures; (a) sol, (b) gel, (c) sol containing AgOTf (0.01 equiv), and (d) gel containing $\operatorname{AgOTf}(0.01$ equiv), (left); Field-emission scanning electron micrographs (FE-SEM) of an air-dried gel (xerogel) with 1, spattered with $\mathrm{Pt}$ under an electric current of $15 \mathrm{~mA}$ at $10 \mathrm{~Pa}$ for $10 \mathrm{~s}$ (right). Adapted with permission from ref. [27]. Copyright 2005 American Chemical Society. 

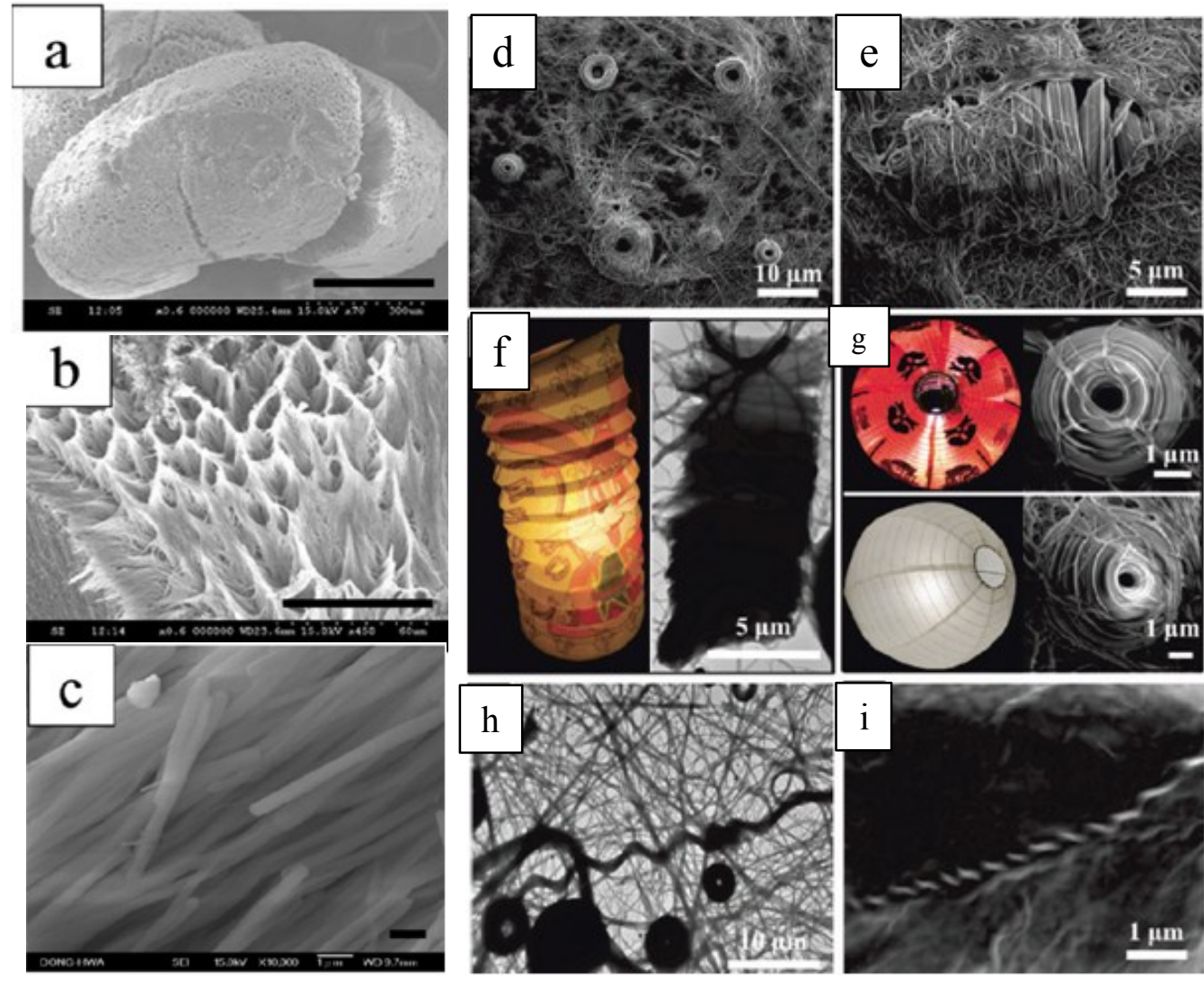

Figure 3. Representative scanning electron microscopic (SEM) micrographs of solid $\left[\mathrm{Au}\left(\mathrm{Cl}_{2} \text {,amide-imy }\right)_{2}\right][\mathrm{Br}]$ from hot $\mathrm{MeOH}$. (a) porous, donut-shaped feature as seen under low magnification; (b) porous surface for a magnified section and (c) fibrous microstructure under high magnification. (bar $=300,60$, and $1 \mu \mathrm{m}$, respectively), (left); (d,e) are representative SEM micrographs of the xerogel of $\left[\mathrm{Au}\left(\mathrm{Cl}_{2} \text {, amide-imy }\right)_{2}\right]\left[\mathrm{NO}_{3}\right]$ from dimethyl sulfoxide (DMSO); (f) A transmission electron microscopic (TEM) image of the xerogel showing a lantern-shaped morphology, picture of the lantern.; (g) SEM images of lantern-shaped fibrous bundles of xerogel; (h) the TEM image of fibers, lantern-shaped fibrous bundles, and a helical like belt; (i) SEM image of the xerogel from $\left[\mathrm{Au}\left(\mathrm{C}_{18} \text {,amide-imy }\right)_{2}\right]\left[\mathrm{NO}_{3}\right]$ showing a helical belt (right). Adapted with permission from ref. [36]. Copyright 2012 American Chemical Society.

Chi-Ming Che and co-workers reported in 2012 a dual-functionalized supramolecular polymer (SP) self-assembled from two cyclometalated $\mathrm{Au}(\mathrm{III})$ complexes (Compound 6, Figure 1) in acetonitrile [41]. Transmission electron and scanning electron micrographs (Figure 4) of 6-SP revealed partially aligned nanofibers with diameters and lengths of about $50 \mathrm{~nm}$ and tens of micrometers, respectively. Partial entanglement of these nanofibers accounts for the high viscosity at high concentration of 6 (20 mm).

A ${ }^{1} \mathrm{H}$ nuclear magnetic resonance (NMR) study on 6 in $\mathrm{CD}_{3} \mathrm{CN}$ at different concentrations and temperatures revealed that the amino group of the guanamine-like moiety of the ligand is involved in hydrogen-bonding interactions in the self-assembly of Complex 6. On the basis of all the studies included, a one-dimensional structure of 6-SP with alternating hydrogen-bonding and $\pi$ - $\pi$ stacking interactions between two cations of $\mathbf{6}$ was proposed by the authors. On the other hand, they demonstrated that polymer 6-SP displayed sustained cytotoxicity and selective cytotoxicity toward cancerous cells. 


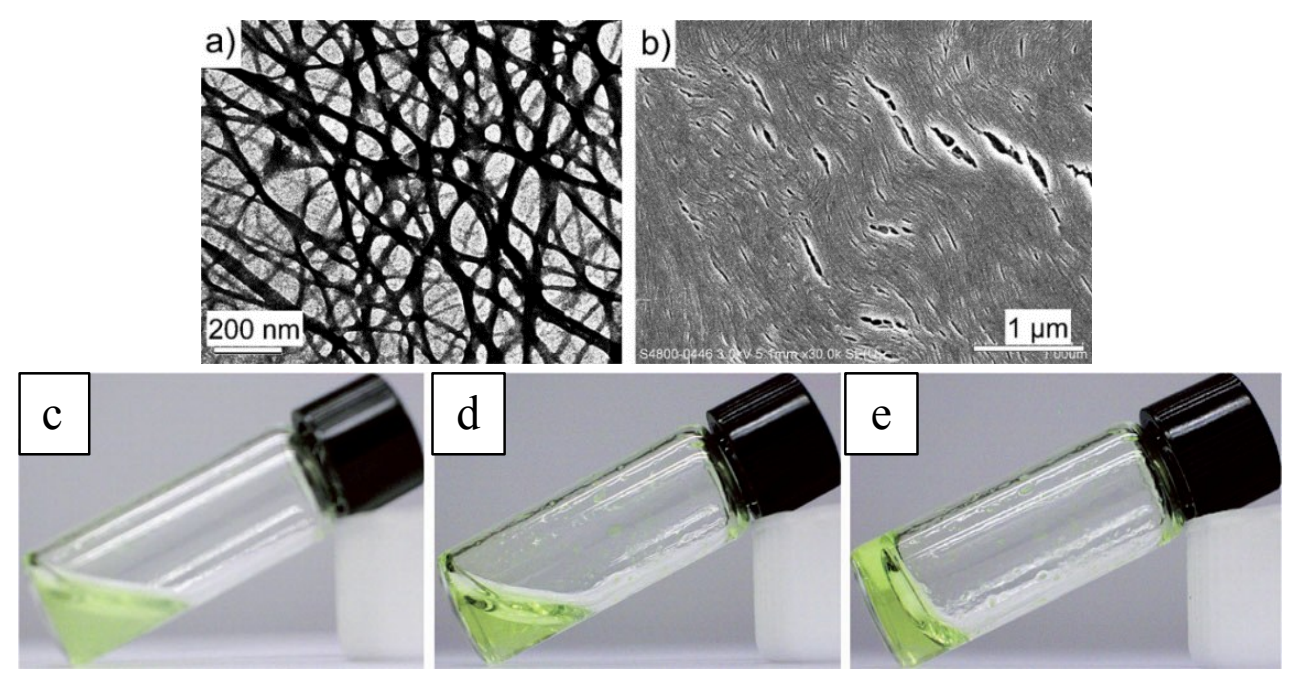

Figure 4. (a) TEM image, (b) SEM images of 6-SP (above); Photographs showing formation of the viscous fluid (supramolecular polymer) of 6 in $\mathrm{CH}_{3} \mathrm{CN}$. (c) Suspension of 6 at $298 \mathrm{~K}$; (d) Dissolution of $\mathbf{6}$ on heating at 323 K; (e) Formation of viscous fluid (6-SP) after cooling the solution in (d) to $298 \mathrm{~K}$ (below). Adapted with permission from ref. [41]. Copyright 2012 John Wiley and Sons.

Alkynyl gold complexes comprise a promising area in this field. A series of luminescent bis-cyclometalated alkynylgold(III) complexes were synthesized and characterized by Yam's group and reported last year [1]. The gelation properties of these complexes were tested in various organic solvents of different polarities (DMSO, methanol, hexane, cyclohexane, benzene, and toluene). It was found that the gold(III) complexes with long hydrocarbon chains (Complexes 7 and 8) were capable of forming more stable metallogels in non-polar organic solvents ( $n$-hexane and cyclohexane), probably due to the formation of stronger London dispersive interactions stemming from the long hydrocarbon chains. In particular, the metallogels formed by Complex 7 were observed to present the highest stability. Attempts to obtain metallogelators with all the complexes synthesized showed that with a judicious choice of coordinating ligands, the interplay of non-covalent interactions such as $\pi$ - $\pi$ stacking and London dispersion forces could be readily adjusted for a rational design of metallogels based on the gold(III) system.
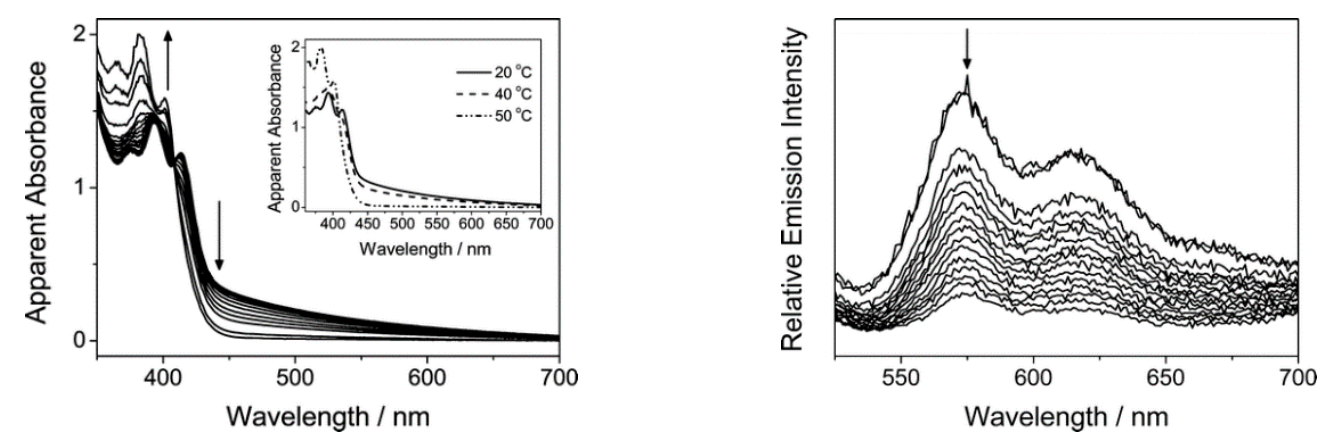

Figure 5. Ultraviolet (UV)-vis absorption spectral traces of the sol-gel phase transition of Complex 4 in hexane upon an increase in the temperature from $10^{\circ} \mathrm{C}$ to $50^{\circ} \mathrm{C}$. Inset: Spectral traces at $20^{\circ} \mathrm{C}, 40^{\circ} \mathrm{C}$, and $50{ }^{\circ} \mathrm{C}$ (left); Corrected emission spectra of the hexane gel of Complex 7 upon an increase in the temperature from $10{ }^{\circ} \mathrm{C}$ to $40{ }^{\circ} \mathrm{C}$ (right). Adapted with permission from ref. [1]. Copyright 2013 American Chemical Society. 
Temperature-dependent ultraviolet (UV)-vis absorption studies were performed with $\mathbf{7}$ in order to clearly observe the gel-to-sol phase transition behavior (Figure 5). The recorded changes at different temperatures showed that the vibronically structured absorption IL bands gradually merged into a broad absorption band when increasing temperature due to the aggregation process and the fact that the absorption tail at $c a .430 \mathrm{~nm}$ tends to disappear. The exhibition of an isosbestic point at $408-410 \mathrm{~nm}$ suggests a clean conversion from the supramolecular assemblies to the monomeric species upon a gel-to-sol transition at elevated temperature. On the other hand, the recorded emission at 570-620 nm due to an ${ }^{3} \mathrm{LLCT}\left[\pi\left(\mathrm{C} \equiv \mathrm{CC}_{6} \mathrm{H}_{4}(\mathrm{OR})_{3}-3,4,5\right) \rightarrow \pi^{*}\left(\mathrm{C}^{\wedge} \mathrm{N}^{\wedge} \mathrm{C}\right)\right]$ transition is observed to be quenched at higher temperatures. This observation was attributed to the fact that in the gel state, the rigidity of the media would increase and result in a reduction of molecular vibrations and motions, such that the non-radiative deactivation pathways could be delayed. However, at higher temperatures, the non-radiative decay would be enhanced resulting in the quenching of the emission.

A novel gold(I) complex based on fluorine (9, Figure 1) was reported very recently by Liu and co-workers [42]. This complex has attracted great attention as it exhibits an interesting aggregate fluorescence change behavior and emits an intense white light in the aggregated state with potential applications in the field of white organic light-emitting devices (WOLEDS). They observed that luminogen 9 is insoluble in water, and increasing the water fraction in the mixed solvent changed the form of the luminogen from a dissolved or well-dispersed state in pure dimethylformamide (DMF) to aggregated particles in the mixtures with high water content. This aggregation state was attributed to the establishment of intermolecular $\pi-\pi$ interactions, $\mathrm{C}-\mathrm{H} \cdots \mathrm{F}$ interactions and intermolecular aurophilic interactions which were responsible for two new emission bands and white light emission.
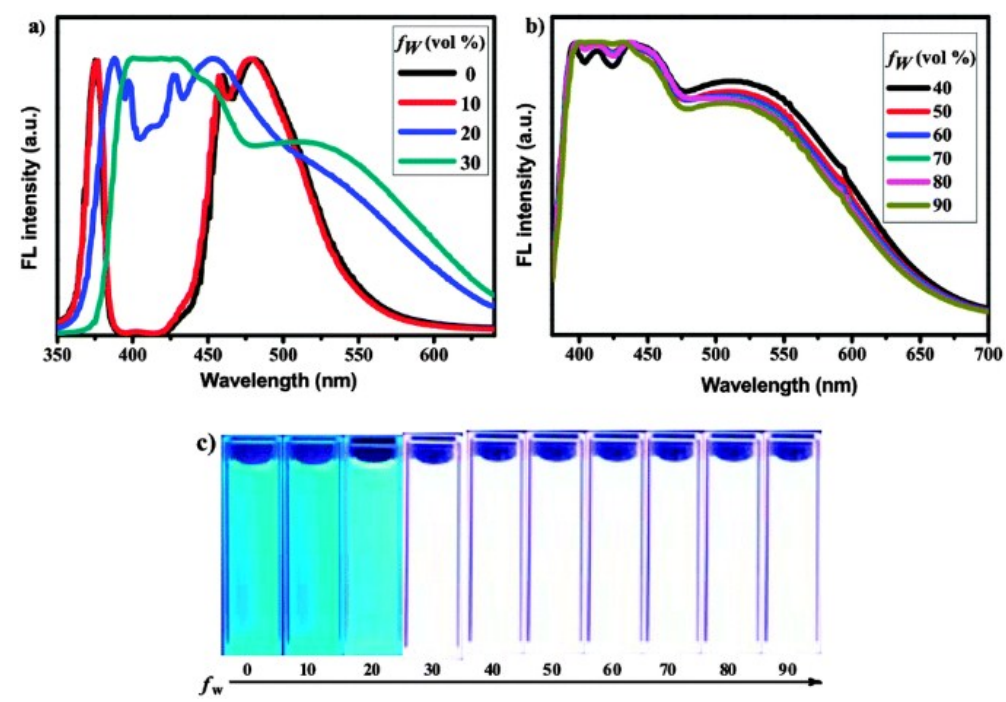

Figure 6. (a) Luminescence spectra of the dilute solutions of $9\left(2.0 \times 10^{-5} \mathrm{~mol} \cdot \mathrm{L}^{-1}\right)$ in dimethylformamide-water $\left(\mathrm{DMF}-\mathrm{H}_{2} \mathrm{O}\right)$ mixtures with different volume fractions of water $(0 \%, 10 \%, 20 \%$ and $30 \%) . \lambda_{\operatorname{exc}}=330 \mathrm{~nm}$; (b) Luminescence spectra of the dilute solutions of $9\left(2.0 \times 10^{-5} \mathrm{~mol} \cdot \mathrm{L}^{-1}\right)$ in $\mathrm{DMF}-\mathrm{H}_{2} \mathrm{O}$ mixtures with different volume fractions of water $(40 \%-90 \%)$. $\lambda_{\text {exc }}=365 \mathrm{~nm}$; (c) The fluorescence images of 9 (concentration: $2.0 \times 10^{-5} \mathrm{~mol} \cdot \mathrm{L}^{-1}$ ) in different $\mathrm{DMF}-\mathrm{H}_{2} \mathrm{O}$ mixtures with different water fractions (fw) under $365 \mathrm{~nm}$ UV irradiation. Reproduced from ref. [42] with permission from The Royal Society of Chemistry. 
This complex emitted a bright white light when the water fraction exceeded 30\%, and the emission bands were broad, with a very high quantum yield ( $c a .65 \%)$ and covered the whole visible range (Figure 6). Interestingly, this white emission was also observed for thin film and solid samples.

This gold(I) complex with white light emission in an aggregate state enriches the family of AIE (aggregation induced emission) compounds that display some interesting potential applications, mainly mechanochromism and chemosensing [43].

\section{Gold Hydrometallogelators}

Very few reports can be found about gold supramolecular hydrogelators. In 2007, Odriozola and co-workers found that glutathione (GSH), a naturally occurring and readily available tripeptide, was able to gelate water when mixed with $\mathrm{Au}$ (III) salts (Figure 7). GSH reacts with gold(III) chloride in water to give the corresponding GS-Au polymer (Complex 10, Figure 8), which forms an almost transparent gel. The polymer is able to gelate 100 times its weight in water, and it is stable for weeks at room temperature. The gel is thermally stable and can be heated to $100{ }^{\circ} \mathrm{C}$ with no observed decomposition [44].

a)

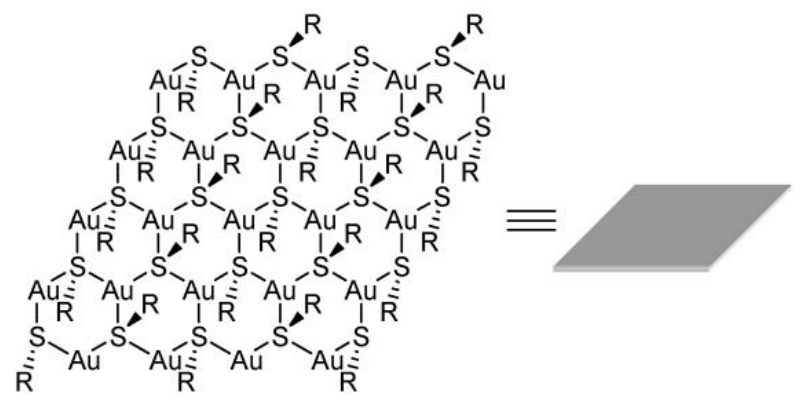

b)

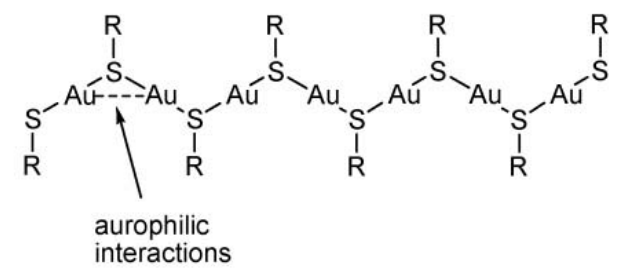

Figure 7. Primary structure of a gold(I) thiolate polymer (10). (a) Top view showing the two-dimensional arrangement; (b) Side view, showing that the Au atoms are placed very close to each other, stabilized by aurophilic interactions. Reproduced from ref. [44] with permission from The Royal Society of Chemistry.

Aurophilic interactions were used for the construction of supramolecular hydrogels for the first time, and the principle can be widely applied for the synthesis of designed hydrogels. These materials have potential biomedical applications since $A u(I)$ thiolates have been used for more than 50 years as therapeutic agents and the variety of naturally occurring and biocompatible thiol-containing molecules is essentially infinite [44].

A few years later, the same group reported on the idea of making a hydrogel with a drug itself acting as the gelator being an emerging alternative for the development of new generation drug-delivery systems [35]. They presented the use of coinage metal complexes containing a thiolate ligand since many drugs contain sulfur derivatives (due to the presence of cysteine residue). It was observed that the gold 
hydrogel (11, Figure 8) presented higher thermal stability than the silver and copper analogous, and could be heated up to the boiling point of water with no phase transition or apparent decomposition observed. A possible explanation was given by the fact that aurophilic interactions are energetically stronger compared to the argentophilic or the cuprophilic ones [45].

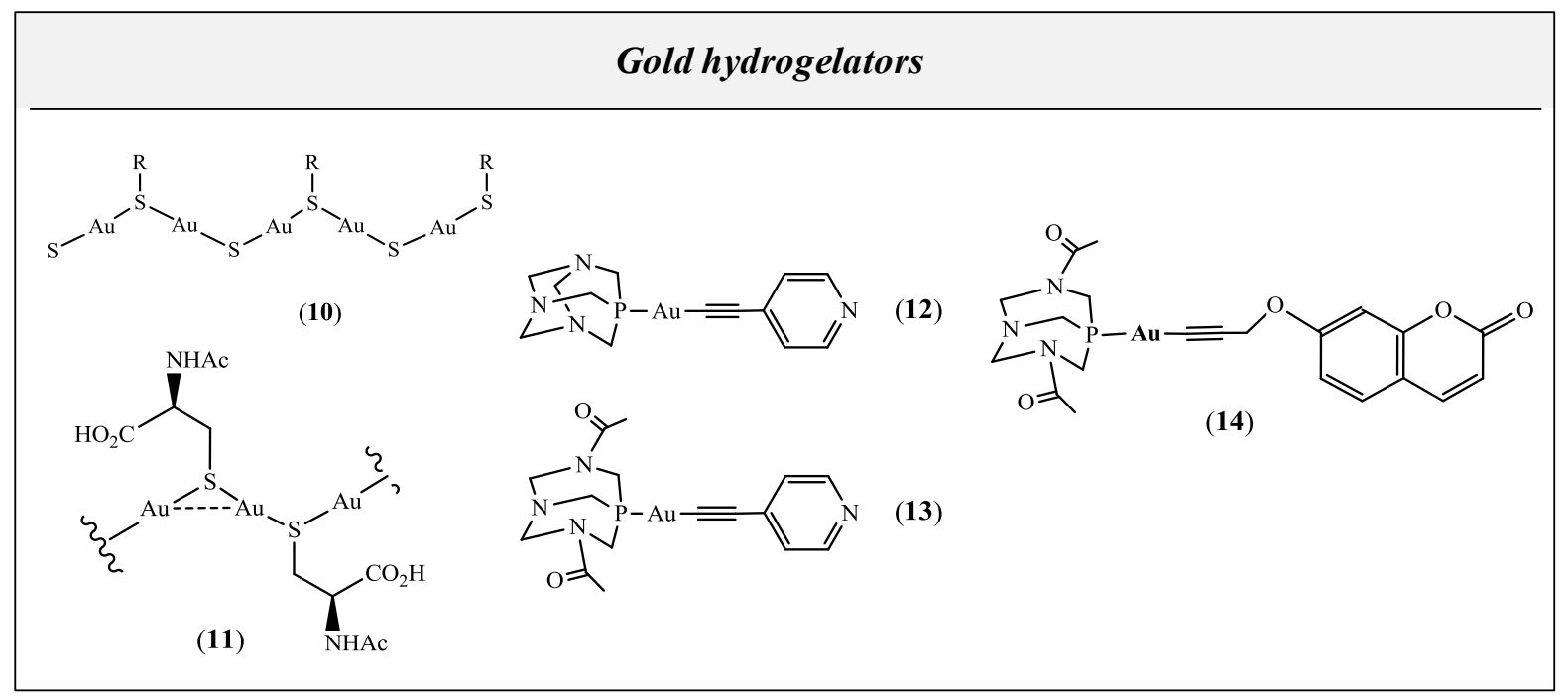

Figure 8. Gold hydrogelators reported in the literature.

The main practical limitation of these hydrogels was that the system gels at $\mathrm{pH}<4$, which can be undesirable for certain biological applications. In fact, UV/vis absorption spectra of the gold hydrogel at different $\mathrm{pH}$ values showed a shoulder absorption band at $\sim 320 \mathrm{~nm}$ at $\mathrm{pH} 3$ which was assigned to the $\mathrm{d}_{\sigma^{*}} \rightarrow \mathrm{p}_{\sigma}$ transition, being an indication of metal $\cdots$ metal interaction. The intensity of this band diminished at higher $\mathrm{pH}$ values, which suggests that the $\mathrm{Au}(\mathrm{I}) \cdots \mathrm{Au}(\mathrm{I})$ interactions became weaker, in agreement with a disaggregation of the gel.

Very recently, we reported on the formation of luminescent organometallic gold(I) hydrogels with the discrete gold(I) complexes [Au(4-pyridylethynyl) (phosph)] (phosph = PTA (1,3,5-triaza-7phosphaadamantane), 12, [28] DAPTA (3,7-diacetyl-1,3,7-triaza-5-fosfabiciclo[3.3.1]nonane), 13)[29]. To the best of our knowledge, these are the first luminescent hydrometallogelators obtained with such simple complexes. The complexes were observed to aggregate in water giving rise to the formation of highly ordered and very long fibers (up to a few millimeters). The simplicity of the chemical structures lead us to carefully analyze these data, and it was observed that the presence of additional acetyl groups on the phosphine (13) induced a higher entanglement of the fibers, as depicted in Figure 9.

Absorption spectra together with $1 \mathrm{D}$ and $2 \mathrm{D}{ }^{1} \mathrm{H}-\mathrm{NMR}$ spectra increased our confidence that $\pi-\pi$ stacking interactions between the $\mathrm{Au}-\mathrm{C} \equiv \mathrm{Cpy}$ units occurred (exciton splitting) together with additional head to tail intermolecular conformations. Additional hydrogen bonding is also expected to be involved in the gelation process of 13. Recent studies carried out also confirm the presence of aurophilic interactions in the formation of these supramolecular structures. These studies are based on the thermodynamic parameters retrieved from the application of Dimicoli and Hélène NMR approach of the isodesmic model [46] in agreement with theoretical calculations. 

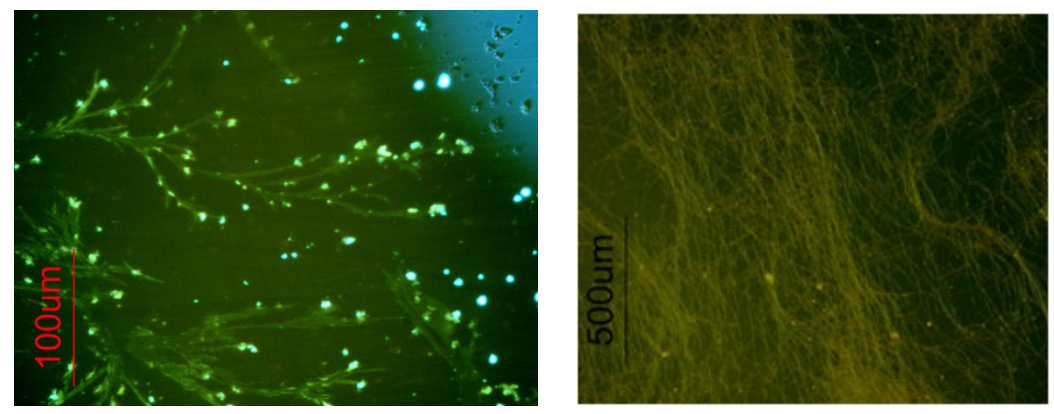

Figure 9. Fluorescence optical microscopy images of 12 (left) and 13 (right) with a 395-440 nm filter.

Moreover, it was observed that electron beam irradiation or heating the samples led to the formation of very homogeneous and small gold nanoparticles whose size could be modulated with the adequate temperature (Figure 10) [29].

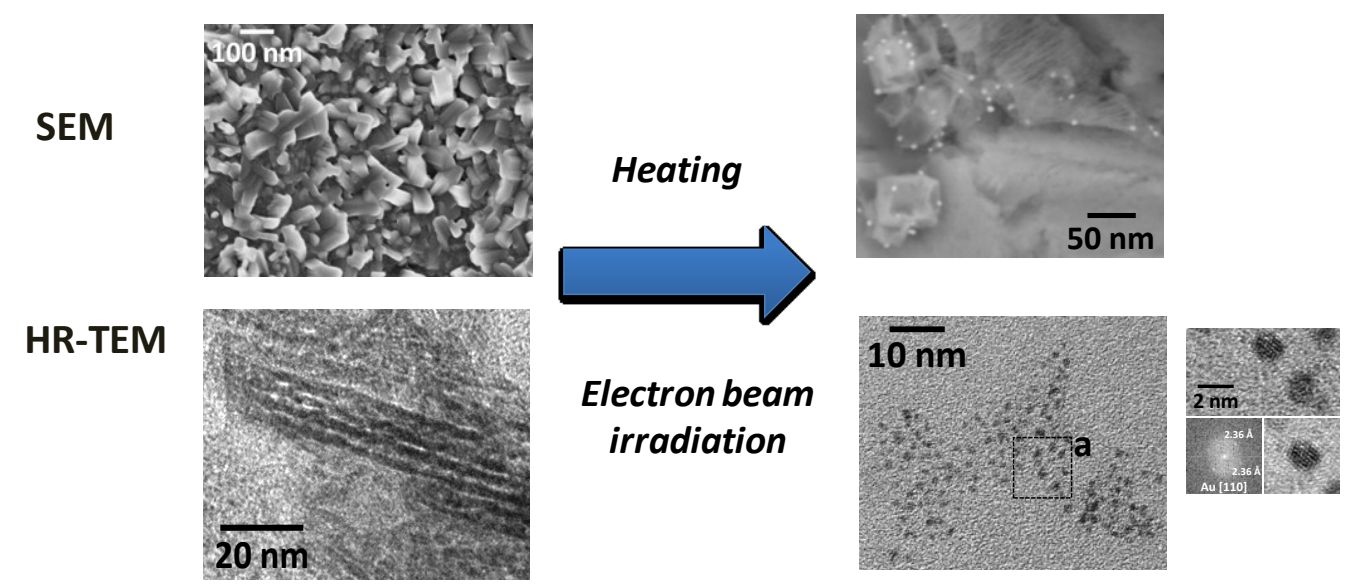

Figure 10. Au NPs formation from hydrogel 13 upon heating the xerogel sample at $200{ }^{\circ} \mathrm{C}$ (above) or irradiation with electrons (below).

A detailed analysis of the formation of the hydrogels with Complexes $\mathbf{1 2}$ and $\mathbf{1 3}$ was conducted very recently with a new luminescent gold(I) hydrogelatos which was also observed to self-assemble into very long fibers $[30,47]$. A coumarin chromophore was chosen instead of a pyridyl unit while phosphine D-Ala-Peptide T-amide (DAPTA) was maintained (14, Figure 8). The presence of a planar aromatic structure and additional atoms suitable to undergo hydrogen bonding (oxygen atoms of the coumarin) were observed to be involved in the aggregation process together with aurophilic interactions. This process was followed by optical microscopy at different concentrations, dynamic light scattering and X-ray crystal structure resolution among other techniques [30]. Interestingly, these weak interactions lead to the formation of a star-shaped 1D polymeric structure and 3D metal-organic framework (MOF)-like structures in the solid state (Figure 11).

Very recent work from P. Besenius' group has been published on the formation of supramolecular assemblies containing $\mathrm{Au}(\mathrm{I})$ alkynyl systems where the use of a peptidic $\mathrm{Au}(\mathrm{I})$-metalloamphiphile has led to the formation of micelles. Although this system does not lead to the formation of a gel, the use of aurophilic interactions within the corresponding supramolecular structure deserves mentioning within this review article [48]. 


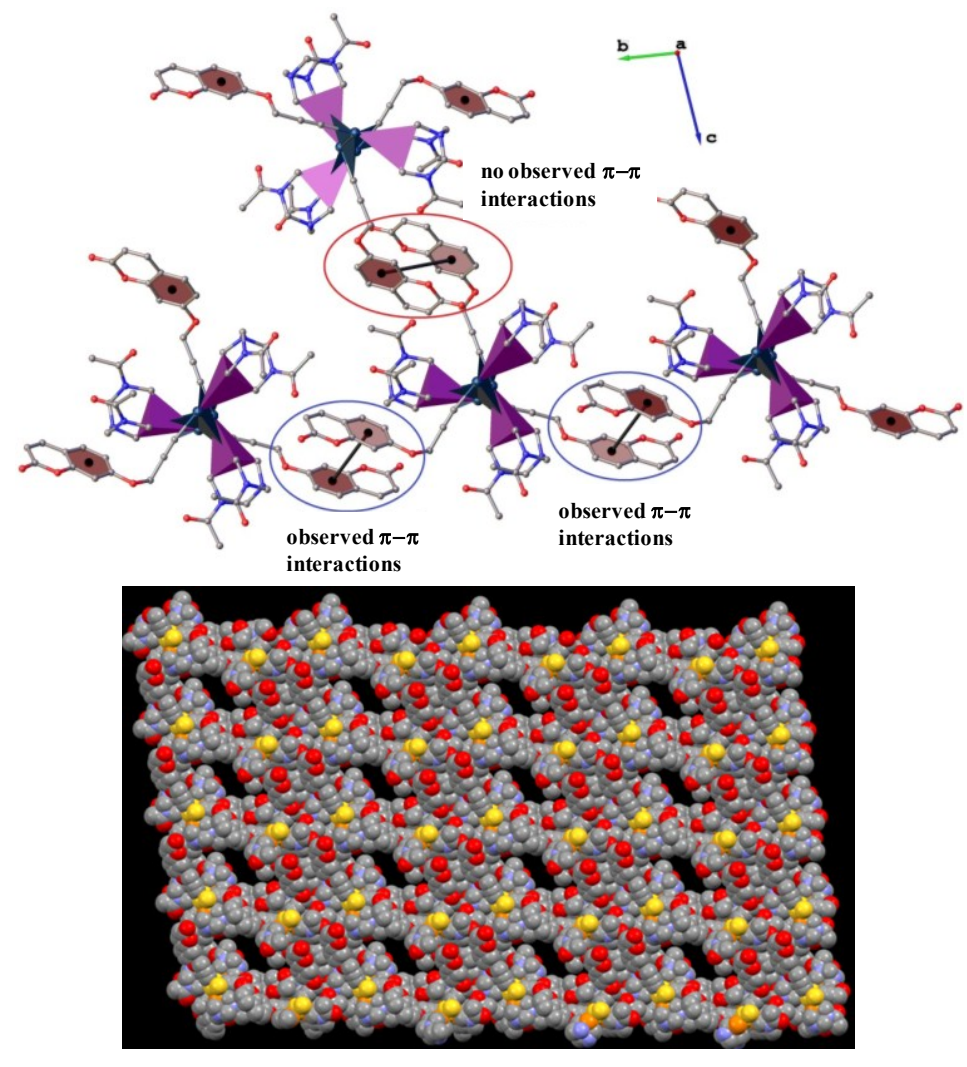

Figure 11. Star-shaped 1-D polymeric structure of 14 showing $\pi-\pi$ stacking interactions (above). 3-D Crystal packing of Complex 1 viewed down the $a$-axis displaying a metal-organic framework (MOF)-like motif (below).

Table 1. Summary of all gold gelators described in this work.

\begin{tabular}{cccccc}
\hline Compound & Au oxidation state & Type of gel & Aurophilicity & Luminescence & Reference \\
\hline 1 & +1 & organogel & yes & yes & 27 \\
2 & +1 & organogel & probably & n.d. & 36 \\
3 & +1 & organogel & probably & n.d. & 36 \\
4 & +1 & organogel & probably & n.d. & 36 \\
5 & +1 & organogel & probably & n.d. & 36 \\
6 & +3 & organogel & no & n.d. & 41 \\
7 & +3 & organogel & no & yes & 1 \\
8 & +3 & organogel & no & yes & 1 \\
9 & +1 & organogel & yes & yes & 42 \\
10 & +1 & hydrogel & yes & n.d. & 44 \\
11 & +1 & hydrogel & yes & n.d. & 35 \\
12 & +1 & hydrogel & yes & yes & 28 \\
13 & +1 & hydrogel & yes & yes & 29 \\
14 & +1 & hydrogel & yes & yes & 30 \\
\hline
\end{tabular}

Taking into consideration all these data, it was found that aurophilic interactions are a common motif in $\mathrm{Au}$ (I) gelators (Table 1) while $\mathrm{Au}(\mathrm{III})$ seems to need an organic functional group as the driving force for the aggregation process. Moreover, it has been observed that most of the $\mathrm{Au}(\mathrm{I})$ complexes display 
interesting luminescence which is known to be affected by the presence of $\mathrm{Au} \cdots \mathrm{Au}$ interactions. These interesting findings allow us to state that gold metallogelators and, in particular, those that display luminescence, are promising research areas in organometallic, supramolecular, and materials chemistry.

\section{Foreseen Applications}

Additionally to the applications envisioned for gold metallogelators, described above, a range of opportunities related with gel applications remain yet to be explored.

As stated above, non-covalent interactions make supramolecular gels responsive and readily tuneable by mechanical, thermal, and chemical external stimuli such as temperature, light, $\mathrm{pH}$, and ultrasound. For example, the increase in viscosity that accompanies gel formation allows conversion of a thermal signal into a mechanical response [49]. In particular, metallogels can possess additional physicochemical properties of metals, and for this reason, metal-containing gels react to a broader range of chemical and physical stimuli [50].

Gels are important in areas such as hydrometallurgy, cosmetics, food processing, and lubrication. Recovery of spilled crude oil or disposal of used cooking oil frequently involves gels or complex microemulsions. Application of gels in drug delivery can be illustrated with the example of active enzymes and bacteria entrapped in apolar gels of gelatin; [51] gel electrolyte solutions are used in lithium battery applications; [52] various gels are used in cosmetics for ointments and creams; [53] many aqueous gels are employed for macromolecular separations, protein crystallization, etc. Comparable applications, specific to organic fluids, using the properties of hindered transport in pores of the gel networks, are also possible for organogels.

When the liquid is evaporated from a gel, the sample shrinks to a xerogel. Capillary forces and liquid-vapor interfaces usually lead to the collapse of the fragile 3D structure. If a supercritical drying process is used at high temperatures and pressures an extremely porous structure, called an aerogel, can be obtained. The remarkable damping of sound and suppression of heat transport of some aerogels portends insulation and acoustic applications. Silica oxides are mostly utilized to form aerogels, but other organometallic gelators may serve the same function.

Membranes with aerogel networks, providing small and large diameter holes, are useful as purification/separation tools [54,55]. These materials, with their networks of microchannels, may be useful as membranes and drug delivery agents.

Gels can also be used to template the synthesis of other porous structures or fibers [56]. The key role of the metal atoms should be highlighted since the particular choice of a metal can determine the resulting morphology and expand the possibilities of construction of different sized and shaped materials.

The advantages of using gels instead of liquid systems lie in the fact that hydrodynamic convection is reduced and various species can be immobilized. Gels find numerous applications in biocatalysis [57], biomembrane mimetics, extraction processes (universal solvents), and preparation of microparticles and nanoparticles [29,38,58].

Low-dimensional linear systems of stacked organometallic compounds can exhibit interesting, long-range electronic and magnetic interactions (e.g., molecular-based ferromagnetism) in the condensed solid-state $[59,60]$. 
Some of the gelling systems may be used as temperature, humidity or anion sensors [61]. Luminescent gels in particular may find applications for linear, anisotropic energy transfer, and sensing applications if the gel transitions impact the spectroscopic properties, which is the case for the Au(I) metallogels exemplified above.

The growing field of sensors is based upon the detection of specific functionalities by donor-acceptor interactions or detection of morphologies, which exploit spatial recognition by cavities, grooves, and channels of the sensor host material [62]. Hence, gels offer an attractive medium for new sensor applications.

Nanochemistry, which utilizes mostly host systems from solid-state chemistry to yield materials with novel electronic, mechanical, and other properties, may take advantage of specific natures of gel networks [63].

Materials, which respond to stimuli by altering their rheological properties, have been subjects of great practical and scientific interest in the recent decades [64]. Electrorheological and magnetorheological systems that are sensitive to electric or magnetic fields, respectively [65,66], are the basis of technologies such as valves, clutches, and dampers [67-70]. Responsive gels can allow rheology control at the microscopic scale, which expands the applicability of stimuli-responsive rheological materials as microvalves, flow sensors for microfluidic systems and nanocarriers for controlled drug delivery systems [71-73]. Supramolecular metallogelators present the tunability required in such applications.

De novo design of gelators with novel structures remains a challenging task. In this sense, aurophilic gels add one more piece to the rational design toolbox.

\section{Conclusions}

A wide range of different applications has been reported for gels in general, from biological to materials chemistry. All of them are based on the porous structure and weak interactions of their network. The additional presence of aurophilic interactions of gold(I) metallogelators and luminescence properties of gold metallogelators in general, should be a new tool for de novo design of gels for such applications.

Metallogelators containing gold metal atoms are still part of an emerging area of research, and the majority of the gel examples reported until now is based on organic solvents. Nevertheless, the number of examples in water is increasing in the last years.

In the case of $\mathrm{Au}(\mathrm{I})$, metallogeators seem consensual that the aurophilic interactions play a key role in the formation of intermolecular bondings responsible for the gelation. Due to the dispersive nature of this interaction it is expected to play an even more important role in the case of hydrogels, where it will contribute to the increase of the hydrophobic interactions.

Less examples are shown containing the Au(III) ion, but they have been increasing in the last years. In this last case, the ligand motifs dominate the aggregation leading to the global process of gel formation, through the summation of weak interactions such as H-bonding, London dispersion forces, or $\pi-\pi$ stacking.

\section{Acknowledgments}

The support and sponsorship provided by COST Action CM1005 is acknowledged. The authors are also grateful to the Ministerio de Ciencia e Innovación of Spain (Project CTQ2012-31335) and Fundação 
para a Ciência e Tecnologia of Portugal (PTDC/QUI-QUI/112597/2009; PEst-C/EQB/LA0006/2011) for financial support.

\section{Conflicts of Interest}

The authors declare no conflict of interest.

\section{References}

1. Au, V.K.-M.; Zhu, N.; Yam, V.W.-W. Luminescent metallogels of bis-cyclometalated alkynylgold(III) complexes. Inorg. Chem. 2013, 52, 558-567.

2. Sangeetha, N.M.; Maitra, U. Supramolecular gels: Functions and uses. Chem. Soc. Rev. 2005, 34, 821-836.

3. Piepenbrock, M.-O.M.; Lloyd, G.O.; Clarke, N.; Steed, J.W. Metal- and anion-binding supramolecular gels. Chem. Rev. 2010, 110, 1960-2004.

4. Peng, K.; Tomatsu, I.; Kros, A. Light controlled protein release from a supramolecular hidrogel. Chem. Commun. 2010, 46, 4094-4096.

5. Saha, S.; Bachl, J.; Kundu, T.; Díaz Díaz, D.; Banerjee, R. Dissolvable metallohydrogels for controlled release: Evidence of a kinetic supramolecular gel phase intermediate. Chem. Commun. 2014, 50, 7032-7035.

6. Tam, A.Y.-Y.; Yam, V.W.-W. Recent Advances in metallogels. Chem. Soc. Rev. 2013, 42, 1540-1567.

7. Banerjee, S.; Das, R.K.; Maitra, U. Supramolecular gels "in action". J. Mater. Chem. 2009, 19, 6649-6687.

8. Segarra-Maset, M.D.; Nebot, V.J.; Miravet, J.F.; Escuder, B. Control of molecular gelation by chemical stimuli. Chem. Soc. Rev. 2013, 42, 7086-7098.

9. Wei, Q.; James, S.L. A metal-organic gel used as a template for a porous organic polymer. Chem. Commun. 2005, 12, 1555-1556.

10. Ono, Y.; Nakashima, K.; Sano, M.; Kanekiyo, Y.; Inoue, K.; Hojo, J.; Shinkai, S. Organic gels are useful as a template for the preparation of hollow fiber silica. Chem. Commun. 1998, 1477-1478.

11. Li, W.; Kim, Y.; Li, J.; Lee, M. Dynamic self-assembly of coordination polymers in aqueous solution. Soft Matter 2014, 10, 5231-5242.

12. Ajayaghosh, A.; Praveen, V.K.; Vijayakumar, C.; George, S.J. Molecular wire encapsulated into $\pi$ organogels: Efficient supramolecular light-harvesting antennae with color-tunable emission. Angew. Chem. Int. Ed. 2007, 46, 6260-6265.

13. Dzolic, Z.; Cametti, M.; Dalla Cort, A.; Mandolini, L.; Zinic, M. Fluoride-responsive organogelator based on oxalamide-derived anthraquinone. Chem. Commun. 2007, 3535-3537.

14. Rodriguez-Llansola, F.; Miravet, J.F.; Escuder, B. A supramolecular hydrogel as a reusable heterogeneous catalyst for the direct aldol reaction. Chem. Commun. 2009, 7303-7305.

15. Zhang, J.; Su, C.-Y. Metal-organic gels: From discrete metallogelators to coordination polymers. Coord. Chem. Rev. 2013, 257, 1373-1408.

16. Jung, J.H.; Lee, J.H.; Silverman, J.R.; John, G. Coordination polymer gels with important environmental and biological applications. Chem. Soc. Rev. 2013, 42, 924-936. 
17. Mayoral, M.J.; Fernández, G. Metallosupramolecular amphiphilic $\pi$-systems. Chem. Sci. 2012, 3, $1395-1398$.

18. Rest, C.; Mayoral, M.J.; Fucke, K.; Schellheimer, J.; Stepanenko, V.; Fernández, G. Self-Assembly and (Hydro)gelation Triggered by Cooperative $\pi-\pi$ and Unconventional $\mathrm{C}-\mathrm{H} \cdots \mathrm{X}$ Hydrogen Bonding Interactions. Angew. Chem. Int. Ed. 2014, 53, 700-705

19. Buhler, G.; Feiters, M.C.; Nolte, R.J.M.; Dotz, K.H. A metal-carbene carbohydrate amphiphile as a low-molecular-mass organometallic gelator. Angew. Chem. Int. Ed. 2003, 42, 2494-2497.

20. Díaz, D.D.; Kühbeck, D.; Koopmans, R.J. Stimuli-responsive gels as reaction vessels and reusable catalysts. Chem. Soc. Rev. 2011, 40, 427-448.

21. Bull, S.R.; Guler, M.O.; Bras, R.E.; Meade, T.J.; Stupp, S.I. Self-assembled peptide amphiphile nanofibers conjugated to MRI contrast agents. Nano Lett. 2005, 5, 1-4.

22. Mauro, M.; Aliprandi, A.; Septiadi, D.; Kehra, N.S.; de Cola, L. When self-assembly meets biology: Luminescent platinum complexes for imaging applications. Chem. Soc. Rev. 2014, 43, 4144-4166.

23. Kawano, S.; Fujita, N.; Shinkai, S. A coordination gelator that shows a reversible chromatic change and sol-gel phase-transition behavior upon oxidative/reductive stimuli. J. Am. Chem. Soc. 2004, 126, 8592-8593.

24. Vermonden, T.; Censi, R.; Hennink, W.E. Hydrogels for Protein Delivery. Chem. Rev. 2012, 112, 2853-2888.

25. Steed, J.W. Supramolecular gel chemistry: Developments over the last decade. Chem. Commun. 2011, 47, 1379-1383.

26. Strassert, C.A.; Chien, C.-H.; Galvez Lopez, M.D.; Kourkoulos, D.; Hertel, D.; Meerholz, K.; de Cola, L. Switching on luminescence by the self-assembly of a platinum(II) complex into gelating nanofibers and electroluminescent films. Angew. Chem. Int. Ed. 2011, 50, 946-950

27. Kishimura, A.; Yamashita, T.; Aida, T. Phosphorescent organogels via "metallophilic" interactions for reversible RGB-color switching. J. Am. Chem. Soc. 2005, 127, 179-183.

28. Gavara, R.; Llorca, J.; Lima, J.C.; Rodríguez, L. A luminescent hydrogel based on a new Au(I) complex. Chem. Comm. 2013, 49, 72-74.

29. Aguiló, E.; Gavara, R.; Lima, J.C.; Llorca, J.; Rodríguez, L. From Au(I) organometallic hydrogels to well-defined $\mathrm{Au}(0)$ nanoparticles. J. Mat. Chem. C 2013, 1, 5538-5547.

30. Moro, A.J.; Rome, B.; Aguiló, E.; Arcau, J.; Puttreddy, R.; Rissanen, K.; Lima, J.C.; Rodríguez, L. Coumarin based gold(I)-alkynyl complex: A new class of supramolecular hydrogelator. Org. Biomol. Chem. 2015, doi:10.1039/c4ob02077d.

31. Lima, J.C.; Rodríguez, L. Applications of gold(I) alkynyl systems: A growing field to explore. Chem. Soc. Rev. 2011, 40, 5442-5456.

32. Lanigan, N.; Wang, X. Supramolecular chemistry of metal complexes in solution. Chem. Commun. 2013, 49, 8133-8144.

33. Schmidbaur, H. The aurophilicity phenomenon: A decade of experimental findings, theoretical concepts and emerging applications. Gold Bull. 2000, 33, 3-10.

34. Schmidbaur, H.; Schier, A. Argentophilic interactions. Angew. Chem. Int. Ed. 2014, doi:10.1002/anie.201405936. 
35. Casuso, P.; Carrasco, P.; Loinaz, I.; Grande, H.J.; Odriozola, I. Converting drugs into gelators: Supramolecular hydrogels from $\mathrm{N}$-acetyl-L-cysteine and coinage-metal salts. Org. Biomol. Chem. 2010, 8, 5455-5458.

36. Hsu, T.H.T.; Naidu, J.J.; Yang, B.-J.; Jang, M.-Y.; Lin, I.J.B. Self-assembly of silver(I) and gold(I) $\mathrm{N}$-heterocyclic carbene complexes in solid state, mesophase, and solution. Inorg. Chem. 2012, 51, 98-108.

37. Estroff, L.A.; Hamilton, A.D. Water gelation by small organic molecules. Chem. Rev. 2004, 104, 1201-1218.

38. Terech, P.; Weiss, R.G. Low molecular mass gelators of organic liquids and the properties of their gels. Chem. Rev. 1997, 97, 3133-3160.

39. Xing, B.; Choi, M.F.; Xu, B. A stable metal coordination polymer gel based on a calix[4]arene and its "uptake" of non-ionic organic molecules from the aqueous phase. Chem. Commun. 2002, 4, 362-363.

40. Van Esch, J.H.; Feringa, B.L. New functional materials based on self-assembling organogels: From serendipity towards design. Angew. Chem. Int. Ed. 2000, 39, 2263-2266.

41. Zhang, J.-J.; Lu, W.; Sun, R.W.-Y.; Che, C.-M. Organogold(III) supramolecular polymers for anticancer treatment. Angew. Chem. Int. Ed. 2012, 51, 4882-4886.

42. Chen, Z.; Wu, D.; Han, X.; Liang, J.; Yin, J.; Yu, G.-A.; Liu, S.H. A novel fluorene-based gold(I) complex with aggregate fluorescence change: A single-component white light-emitting luminophor. Chem. Commun. 2014, 50, 11033-11035.

43. Zhang, X.; Chi, Z.; Zhang, Y.; Liu, S.; Xu, J. Recent advances in mechanochromic luminescent metal complexes. J. Mater. Chem. C 2013, 1, 3376-3390.

44. Odriozola, I.; Loinaz, I.; Pomposo, J.A.; Grande, H.J. Gold-glutathione supramolecular hydrogels. J. Mater. Chem. 2007, 17, 4843-4845.

45. Pyykko, P. Theoretical Chemistry of Gold. Angew. Chem. Int. Ed. 2004, 43, 4412-4456.

46. Dimicoli, J.-L.; Hélène, C. Complex-formation between purine and indolederivatives in aqueous-solutions-proton magnetic-resonance studies. J. Am. Chem. Soc. 1973, 95, 1036-1044.

47. Arcau, J.; Andermark, V.; Aguiló, E.; Gandioso, A.; Moro, A.; Cetina, M.; Lima, J.C.; Rissanen, K.; Ott, I.; Rodríguez, L. Luminescent alkynyl-gold(I) coumarin derivatives and their biological activity. Dalton Trans. 2014, 43, 4426-4436.

48. Kemper, B.; Hristova, Y.R.; Tacke, S.; Stegemann, L.; van Bezouwen, L.S.; Stuart, M.C.A.; Klingauf, J.; Strassert, C.A.; Besenius, P. Facile synthesis of a peptidic Au(I)-metalloamphiphile and its self-assembly into luminescent micelles in water. Chem. Commun. 2014, doi:10.1039/c4cc03868a.

49. De Hatten, X.; Bell, N.; Yufa, N.; Christmann, G.; Nitschke, J.R. A dynamic covalent, luminescent metallopolymer that undergoes sol-to-gel transition on temperature rise. J. Am. Chem. Soc. 2011, 133, 3158-3164.

50. Fages, F. Metal coordination to assist molecular gelation. Angew. Chem. Int. Ed. 2006, 45, 1680-1682.

51. Haering, G.; Luisi, P.L. Hydrocarbon gels from water-in-oil microemulsions. J. Phys. Chem. 1986, $90,5892-5895$. 
52. Ue, M.; Kaitoh, M.; Yazsukawa, E.; Mori, S. A new gelling agent and its application as a solid electrolyte for lithium batteries. Electrochim. Acta 1993, 38, 1301-1302.

53. De Vringer, T.; Joosten, J.G.H.; Junginger, H.E. A study of the gel structure in a nonionic O/W cream by X-ray diffraction and microscopic methods. Colloid Polym. Sci. 1987, 265, 167-179.

54. Hafkamp, R.J.H.; Kokke, P.A.; Danke, I.M.; Guerts, H.P.M.; Rowan, A.E.; Feiters, M.C.; Nolte, R.J.M. Organogel formation and molecular imprinting by functionalized gluconamides and their metal complexes. Chem. Commun. 1997, 545-546.

55. Gu, W.; Lu, L.; Chapman, G.B.; Weiss, R.G. Polymerized gels and "reverse aerogels" from methyl methacrylate or styrene and tetraoctadecylammonium bromide as gelator. Chem. Commun. 1997, 543-544.

56. Llusar, M.; Sanchez, C. Inorganic and hybrid nanofibrous materials templated with organogelators. Chem. Mater. 2008, 20, 782-820.

57. Barreira, G.; Ferreira, A.S.D.; Vidinha, P.; Cabral, J.M.S.; Martinho, J.M.G.; Lima, J.C.; Cabrita, E.J.; Barreiros, S. Assessing diffusion in enzyme loaded sol-gel matrices. RSC $A d v$. 2014, 4, 25099-25105.

58. Rees, G.D.; Robinson, B.H. Microemulsions and organogels: Properties and novel applications. Adv. Mater. 1993, 5, 608-619.

59. Ricco, M.; Dalcanale, E. Molecular conformation and magnetic behavior of macrocyclic columnar liquid crystals. J. Phys. Chem. 1994, 98, 9002-9008.

60. Albouy, P.A. Structure of langmuir-blodgett films of copper phthalocyanine derivatives. J. Phys. Chem. 1994, 98, 8543-8548.

61. Foster, J.A.; Edkins, R.M.; Cameron, G.J.; Colgin, N.; Fucke, K.; Ridgeway, S.; Crawford, A.G.; Marder, T.B.; Beeby, A.; Cobb, S.L.; et al. Blending gelators to tune gel structure and probe anion-induced disassembly. Chem. Eur. J. 2014, 20, 279-291.

62. Dickert, F.L.; Haunschild, A. Sensor materials for solvent vapor detection-donor-acceptor and host-guest interactions. Adv. Mater. 1993, 5, 887-895.

63. Novak, B.M.; Auerbach, D.; Verrier, C. Low-density, mutually interpenetrating organic-inorganic composite materials via supercritical drying techniques. Chem. Mater. 1994, 6, 282-286.

64. Paulusse, J.M.J.; Sijbesma, R.P. Molecule-based rheology switching. Angew. Chem. Int. Ed. 2006, 45, 2334-2337.

65. Hao, T. Electrorheological fluids. Adv. Mater. 2001, 13, 1847-1857.

66. Jang, I.B.; Kim, H.B.; Lee, J.Y.; You, J.L.; Choi, H.J. Role of organic coating on carbonyl iron suspended particles in magnetorheological fluids. J. Appl. Phys. 2005, 97, 10Q912.

67. De Gans, B.-J.; Hoekstra, H.; Mellema, J. Non-linear magnetorheological behaviour of an inverse ferrofluid. Faraday Discuss. 1999, 112, 209-224.

68. Pan, X.D.; McKinley, G.H. Characteristics of electrorheological responses in an emulsion system. J. Colloid Interface Sci. 1997, 195, 101-113.

69. Ketner, A.M.; Kumar, R.; Davies, T.S.; Elder, P.W.; Raghavan, S.R. A simple class of photorheological fluids: Surfactant solutions with viscosity tunable by light. J. Am. Chem. Soc. 2007, 129, 1553-1559.

70. Sun, K.; Kumar, R.; Falvey, D.E.; Raghavan, S.R. Photogelling colloidal dispersions based on light-activated assembly of nanoparticles. J. Am. Chem. Soc. 2009, 131, 7135-7141. 
71. Gong, C.B.; Lam, M.H.W.; Yu, H.X. The fabrication of a photoresponsive molecularly imprinted polymer for the photoregulated uptake and release of caffeine. Adv. Funct. Mater. 2006, 16, 1759-1767.

72. Düurrschmidt, T.; Hoffmann, H. Electrorheological effects in suspensions of hydrophobically modified saponite. Colloids Surf. A 1999, 156, 257-269.

73. Joshi, Y.M.; Reddy, G.R.K.; Kulkarni, A.L.; Kumar, N.; Chhabra, R.P. Rheological behaviour of aqueous suspensions of laponite: New insights into the ageing phenomena. Proc. R. Soc. A 2008, 464, 469-489.

(C) 2014 by the authors; licensee MDPI, Basel, Switzerland. This article is an open access article distributed under the terms and conditions of the Creative Commons Attribution license (http://creativecommons.org/licenses/by/4.0/). 